\title{
The Logic of the Promotion Decision: In Dubio Pro Patientia
}

Kurt Weyland, University of Texas at Austin

ABSTRACT This essay encourages associate professors to wait to initiate their candidacy for promotion until they have established a clearly sufficient, unchallengeable record of research and publication. To guarantee faculty productivity and intellectual vibrancy, and to provide consistent incentives and rewards, university departments should apply reasonably demanding promotion standards that are equivalent to their tenure criteria. Associate professors have a strong interest in comfortably clearing this promotion hurdle to enhance their professional reputation in the eyes of their departmental colleagues, the university leadership, and external referees. Therefore, they are well advised to bid for the rank of professor only after accumulating a strong record that makes a smooth promotion likely.

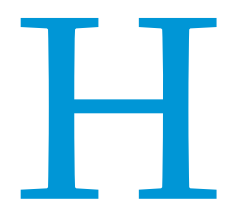
ow can professors make good tenure and promotion decisions? Systematic discussions of the standards and criteria that should guide the principal professional judgments incumbent on faculty members are rare. It is not easy to go beyond general principles and settle on concrete criteria and specific recommendations. In turn, it is unclear how different professional standards affect broader academic goals. For instance, do fairly high promotion thresholds prompt better research and successful publication efforts, or do they have a dispiriting effect on many colleagues? Although political scientists frequently must participate in promotion decisions, they rarely discuss these questions in writing.

This article seeks to close the gap by providing some systematic advice on proper promotion decisions. It addresses normative questions, which cannot be adjudicated by empirical research. Accordingly, this essay constitutes an opinion piece rather than an analysis with scientific-truth claims. It has the modest purpose of advancing some recommendations to stimulate reflection and discussion. The ideas developed herein distill insights I gained during two decades of participation in tenure and promotion decisions in my own universities and-via numerous tenure letters and promotion assessments-in other departments as well. Although most of these evaluations concerned political scientists, my service on a college promotion and tenure committee also provided insight into the academic decision making of many other disciplines.

Kurt Weyland is the Lozano Long Professor of Latin American politics at the University of Texas at Austin. He can be reached at kweyland@austin.utexas.edu.
The reflections in this article were inspired by my earlier essay on promotion issues (Weyland 2011), which developed a clear, firm "logic of the tenure decision." By advocating that in cases of doubt departments should vote against a tenure candidate, this rigorous discussion set a fairly high hurdle for faculty retention. Does this line of reasoning have implications for the subsequent promotion of colleagues who achieved tenure-that is, the step from associate to full professor?

This article attempts to draw out these implications. It argues that departments should apply standards that are similar to those used for tenure decisions in promotions to the rank of professor (for simplicity, hereinafter called the "promotion decision"). Yet, given the differences between the tenure and promotion decisions, this article derives a specific recommendation, which is directed primarily at potential candidates. Because the promotion decision is not on a predefined schedule but rather is initiated by a candidate, associate professors should make a prudent, risk-averse choice and wait until they have established a clear-cut case. In dubio pro patientia: "When in doubt, it is advisable to be patient"-and to keep writing and publishing until the promotion prospects are no longer doubtful.

The reasoning underlying this recommendation is the following: Because university departments need to set high standards for their tenure decisions, equivalent criteria must guide subsequent judgments as well. Therefore, faculty members should bid for promotion only after they have established a strong, unchallengeable record and thus have very good chances to clear the hurdle without problems. To guard and enhance their academic reputation-one of our most important assets-associate 
professors are well advised to present their case for thorough examination and judgment only when they have accumulated an incontrovertible record of scholarly research and publication. The limited benefit of "forcing" an earlier promotion decision does not compensate for the lasting cost of making a negative impression on one's own department, the university's administrative leaders, and the external reviewers-all of whom are likely to have a significant impact on a scholar's subsequent career. Therefore, rushing into the promotion decision does not "pay."

Thus, the basic guideline for promotion decisions is an exhortation to potential candidates-essentially, an appeal to their enlightened self-interest. If associate professors do not have clear prospects of easily clearing the promotion hurdle, they are well advised to wait and establish a stronger record of research and publication. From a candidate's medium- and long-term perspective, it is far preferable to win an "easy" promotion a few years later than to receive lukewarm approval under a cloud of doubt, questions, university department's scholarly vibrancy. The principal goal is to reward colleagues whose track record inspires confidence that their future research and writing will make crucial contributions to their department's academic visibility and standing. Such success is decisive not only for a professor's individual career but also for the collective well-being of a scholarly community. After all, academia has a crucial collective dimension: In a well-run department, everyone benefits from the professional success of their colleagues, which helps the department attract better faculty and students and draw resources and support from the university administration. Therefore, professors have a stake in the research and publication record of their colleagues. What a pleasure it is to be surrounded by interesting, active scholars with whom one can exchange ideas, initiate collaborative projects, and engage in productive competition! By contrast, the presence of "deadwood" can result in low morale and can cause tension about the fairness of burden sharing in a university department.

\section{Colleagues are less likely to trip on a hurdle if they have a good understanding of its difficulty level.}

and criticism. Therefore, my advice to associate professors is this: Give your evaluators-whose judgments will continue to play a crucial role for the remainder of your career-every reason to feel good about supporting your promotion rather than risking that they reluctantly sign off on your case while closing their eyes.

Because the following discussion focuses on research productivity, this essay is meant primarily for research-oriented universities. The more an institution emphasizes teaching, the higher the standards for instructional quality must be and the more it will count in evaluations. At research-oriented universities, satisfactory teaching is regarded widely as sufficient, and teaching itself does not matter very much-which, for the purpose of this article, means that stellar teaching cannot compensate for lackluster research and a meager publication record.

\section{THE IMPORTANCE OF CLEAR, REASONABLY DEMANDING PROMOTION STANDARDS}

For various reasons, professors seem to avoid explicit discussions and rigorous thinking about the standards and criteria that should orient our most important professional judgments. However, the resulting ambiguity and uncertainty tend to create problems for promotion candidates and their departments. Colleagues are less likely to trip on a hurdle if they have a good understanding of its difficulty level. Furthermore, departments that provide a clear sense of the career ladder are more likely to induce the behavior-especially active research and publicationthat allows promotion candidates to clear the hurdles unscathed and, it is hoped, with ease. We all long for unproblematic promotion decisions! There is nothing better than when a candidate establishes a clearly sufficient record so that evaluators can sign off comfortably. The resulting goodwill especially benefits the successful candidate.

Certainly, the standards and criteria that guide promotion decisions must be reasonably demanding. The fundamental purposes of these evaluations are to guarantee high academic quality, induce continuing faculty productivity, and strengthen a
To stimulate academic dynamism and faculty productivity, departments have two crucial responsibilities: (1) support and nurture research and writing and help professors to meet departmental expectations and standards; and (2) at tenure and promotion time, undertake professional, impartial, and rigorous judgments of the candidates' success.

As academics, we have a strong interest in the quality of our departments and in our colleagues' success. With productive colleagues, there is a higher chance of recruiting even better professors and attracting promising $\mathrm{PhD}$ students. Therefore, departments want to spend plentiful resources on enhancing faculty productivity. Moreover, professors can support one another's research and writing; co-authorship is becoming more common. In my experience, working groups in which faculty (and PhD students) read a group member's draft and discuss it collectively yields high payoffs. In addition to offering constructive advice on a specific paper, these groups serve the broader purpose of mentoring. Departments that promote these (certainly time-consuming) collaborative initiatives will encourage faculty productivity and foster collegiality.

Because departments should work hard to nurture academic quality and intellectual energy, they must undertake correspondingly strict evaluations of colleagues' publication efforts and success, applying properly ambitious standards and criteria. Promotion decisions must result in a clear net improvement in faculty quality. Other than outside hiring, which is limited by financial constraints, tenure and promotion decisions constitute the most important means for promoting the dynamism and vibrancy of tenured faculty and full professors, respectively. Departments should use these evaluations to retain and reward those colleagues-and only those colleagues-who have an active research agenda, have proven success in scholarly publication, and possess a strong promise of future productivity. Departments want to achieve continuing improvement and progress and to avoid stagnation. This drive is crucial for faculty morale; working in a department that is on an upward trajectory is an important 
source of motivation and inspiration. Promotion standards, therefore, must align with these forward-looking goals.

Certainly, however, departmental standards and criteria cannot be so high that only the occasional "superstar" clears the hurdle. Excessive ambition would drive away talent, discourage hard-working colleagues, and tense the departmental climate. Promotion should require a good deal of professional effort and success but not become a hopeless quest; otherwise, paralysis occurs. Unrealistic standards also would expose a department to frequent "raiding" by other universities that do not "work" their faculty as hard. Although the academic job market is less con- and intellectual dynamism. The promotion decision constitutes the only regular step in a professor's advance after tenure. Virtually every colleague wants to reach the rank of full professor. This goal is crucial for a department's effort to ensure continued research and publication after tenure. Winning the big prize of permanent employment could, in principle, make academics complacent, lead them to prematurely accept time-consuming administrative appointments, and weaken their concentration on research and writing. In fact, scholarly productivity trends downward over the course of professorial careers, and tenure often results in a significant inflection in this disappointing trajectory.

\section{To suppress these tendencies and induce continued attention to research and publication, university departments must ensure that the goal offull professorship is sufficiently difficult to obtain.}

straining in the current era of financial scarcity and oversupply of well-trained job seekers, the risk of losing accomplished professors counsels against overambitious standards. For these reasons, promotion criteria must be calibrated in a way that puts a department on a clear upward trajectory but does not confront associate professors with a steep uphill battle. Of course, each institution must determine specific standards, particularly depending on its position in the academic market and the importance attributed to research and publication.

This spirit of realistic ambition inspires my clarification of the "logic of the tenure decision" (Weyland 2011). Emphasizing that university tenure constitutes a great, irrevocable reward, my 2011 essay put the burden of proof on the candidate and advocated positive tenure decisions only if an assistant professor had established a strong, unchallengeable record of scholarly research and publication. Given the virtual impossibility of reversing a false-positive tenure decision, I urged rejection in cases of doubt.

Can this "logic" of the tenure decision be usefully extended to the subsequent step of promotion to full professor? The promotion evaluation certainly differs from the tenure vote in crucial ways. Primarily, the stakes are much lower, precisely because the candidate already has won tenure and therefore has become a quasipermanent member of a department. The outcome will not be "up or out" but merely an increase in status and salary.

These diminished stakes may suggest to university departments that the cost of a false-positive promotion decision is low. Excessively "easy" judgments can result, especially because a department must live with the disappointment of an unsuccessful candidate. Moreover, many considerations that can induce departments to deviate from the logic of the tenure decision (Weyland 2011, 359-6o) tend to have even greater influence on promotion decisions. After all, associate professors tend to be better "connected" than assistant professors, they are less easily replaceable, and so forth. Departments therefore may be tempted to make excessively lenient promotion decisions.

However, such leniency would cause broader problems by hindering a department's quest for academic quality and scholarly productivity. Considering only the direct stakes of the promotion decision reflects an improperly narrow perspective. Instead, promotion to "full" is an integral step on a professor's career ladder and part of a department's effort to improve its scholarly standing
To suppress these tendencies and induce continued attention to research and publication, university departments must ensure that the goal of full professorship is sufficiently difficult to obtain. Indeed, resources permitting, they should introduce additional career steps via endowed professorships; these attractive positions would give well-performing colleagues further incentives to continue their productivity (and receive support through research funds and teaching release). Moreover, universities should gradually make post-tenure reviews more rigorous to maintain useful pressure at the lower end of faculty performance. It is hoped that academics have a genuine interest in adding to scholarly knowledge and maintaining this "fire" even after decades on the job. However, a little scrutiny, backed up by a proper mix of rewards and sanctions, cannot hurt.

For these reasons, the expectations applied in tenure decisions also must guide subsequent promotion decisions. Because tenure depends on a track record that gives evaluators confidence about strong future performance, evidence of such accomplishments must be required for advancing tenured faculty to the next career step. A department's academic quality and chances for improvement suffer if tenure is comparatively difficult but promotion to full professor is excessively easy. After all, faculty members who achieve tenure continue about three quarters of their career after this milestone. For the intellectual climate of a department, it therefore is essential to complement the nurturing efforts mentioned previously by maintaining proper incentives and rewards, especially via the promotion decision. Because departments should apply reasonably demanding standards for tenure, they must use the same standards for the promotion decision. Only this consistency can ensure continued faculty productivity and foster a dynamic, high-quality scholarly community. Basic fairness also demands consistency: It makes little sense to force assistant professors to clear a high hurdle and then significantly lower the bar when, as associate professors, those colleagues face the other big step on their career ladder. Why apply lower standards for a higher position? Promotion criteria must be equal and uniform along a professor's rise in the professional hierarchy.

\section{IMPLICATIONS FOR PROMOTION CANDIDATES: THE BENEFITS OF PATIENCE}

Because tenured colleagues who want to be promoted to full professor must fulfill the same standards that departments should 
rigorously apply in tenure decisions, they have every incentive not to trip over this reasonably high hurdle. Compared to assistant professors, however, associate professors can choose when to bid for promotion. Whereas most tenure decisions arise on a fixed schedule, promotion decisions are initiated by a candidate. Therefore, associate professors must consider carefully when they want to begin the evaluation process.

It is a common human tendency to overestimate one's accomplishments and qualities. Far more than $50 \%$ of all people rate themselves as above-average drivers, parents, spouses, andprobably-professors. Knowing the effort it took to figure out a difficult intellectual problem, professors tend to be impressed by their own contributions to scholarship. By contrast, after their discovery, colleagues' findings may seem so logical and evident that observers may underestimate their significance. This widespread human tendency of overrating one's achievements can tempt associate professors to bid for promotion too soon.

Concrete incentives reinforce the desire to take this important step prematurely. Financial need can fuel this urge because a raise in salary accompanies promotion. The increase in status that entry into the "full" establishment entails as well as the end of the uncertainty that every upcoming evaluation involves are attractive. Full professors also tend to command greater influence in a department-for instance, by gaining the right to vote on the promotion of the remaining associate professors. Thus, there are rational motives for seeking promotion early.

Moreover, the lower stakes of the promotion decision, which does not endanger tenure, can induce a certain willingness to take risk. Whereas the benefits of a successful promotion are clear, a denial may seem to merely maintain the status quo. After all, whereas unsuccessful tenure candidates are "out," associate professors who fail to move "up" nevertheless stay "in." Some promotion candidates therefore may gamble that their colleagues want to avoid awkward situations, give them the benefit of the doubt, and approve their promotion case even if it is weak. The risks seem low: if a premature promotion bid fails, the candidate can try again later. For these reasons, there the hurdle comfortably. When in doubt, an associate professor should wait: In dubio pro patientia.

The essential reason for this patient approach is as follows: One of the main assets of professors is their professional reputation, which crucially shapes their standing in their field, their departmental influence, and their future career opportunities. Professors with strong reputations are more likely to receive invitations to interesting lectures and conferences; colleagues are more willing to comment on their work and contribute to their endeavors; and good students are more likely to be attracted to their departments. Informal clout in departmental decision making also depends on professional reputation. Moreover, path dependency prevails: Current standing provides benefits that facilitate further enhancements in reputation. Success begets success, whereas weakness leads to increasing marginalization. Therefore, professors have good reasons to invest in their reputation and to avoid making a negative or questionable impression on important colleagues.

Certainly, professors' reputation arises from their academic achievements throughout their entire career. However, there are two crucial occasions when departmental colleagues, university administrators, and major experts in a scholarly field evaluate academics' accomplishments and thoroughly and comprehensively assess their promise: the tenure and the promotion decisions. On these occasions, the most relevant internal and external evaluators carefully read a colleague's work and systematically judge its quality. The impression that this intensive engagement with a professor's research and writing creates likely persists and has a lasting impact. A professor who receives a ringing endorsement gains a clear boost in reputation, but a colleague who fails or limps across the finish line suffers a significant reduction in standing.

Judgments established at promotion time matter greatly because the departmental colleagues, university administrators, and external referees who play a crucial role in these evaluations likely participate in future decisions that affect a professor's career. The image they form when thoroughly and carefully study-

\section{For a successful career, it makes much more sense to dispassionately evaluate one's own accomplishments and prospects; to take seriously honest advice from one's department; and to continue working until one has accumulated a clear-cut, unchallengeable record of research and publication.}

can be a temptation for associate professors to "force" the promotion decision by initiating it too early and betting on their colleagues' reluctance to cast a negative vote.

The basic purpose of this article is to advise strongly against this temptation. The enlightened self-interest of associate professors demands that they suppress these short-term calculations and guard against the human tendency of self-overestimation. For a successful career, it makes much more sense to dispassionately evaluate one's own accomplishments and prospects; to take seriously honest advice from one's department; and to continue working until one has accumulated a clear-cut, unchallengeable record of research and publication. To avoid running afoul of departmental standards, it is best to ensure that one can clear ing a professor's record will shape their assessments in the future. Such "anchoring" has repercussions because professors face continuing evaluations throughout their careers. In particular, access to resources such as funding or teaching release-which are crucial for scholarly productivity and further career prospects-often depend on support from colleagues and decision makers who participated in the promotion decision.

Department chairs, for instance, often must endorse a professor's internal leave application and rank-order intradepartmental competitors. If a colleague forced the chair into an uncomfortable position by "pushing" a premature promotion case, the chair probably will be less supportive. Similarly, many grants require recommendations from senior scholars in one's field. Yet, these 
prominent figures also evaluate a professor's promotion case. If they received a meager file and struggled with a borderline case, they are unlikely to provide strong endorsements in the future. Thus, because professors frequently depend on the evaluation and support of other scholars, it is inadvisable to create a negative impression when facing a systematic, comprehensive assessment. Instead of a candidate choosing to bid for promotion early, it makes more sense to accumulate a strong record, guarantee approval from all sides, and reap the fruits of this prudence for the remainder of one's career. likely constitutes a worthwhile investment in one's professional standing. From a long-term perspective, it makes sense to resist the temptation of an early and possibly premature candidacy, to write another article or two, or to wait until the new book is finally in print. Because associate professors choose the timing, they should allow enlightened self-interest to guide their calculations and prudently work toward giving their promotion case a high probability of success. If they emerge bruised from the promotion decision, the blemish to their academic reputation persists

\section{... a department that consistently approves strong candidates gains credibility and support and may reap the rewards through special resource allocations.}

Premature or unsuccessful promotion cases also carry costs for a department, thereby weakening its resource competition inside a university. When a department puts forward weak candidates, it creates a negative impression among top administrators, who then face the unpleasant task of reversing the decision. By contrast, a department that consistently approves strong candidates gains credibility and support and may reap the rewards through special resource allocations. Therefore, departmental leaders have a clear interest in discouraging premature applications for promotion. Associate professors who "push" for promotion too early are acting against not only their own enlightened self-interest but also departmental interests.

For these individual and collective reasons, protecting one's professional reputation should far outweigh short-term interests in salary increase and the "full" professor title. Waiting to round out one's publication profile and thus make a successful promotion for a long time. Because difficult promotion cases put evaluators in an awkward position, departmental colleagues, university administrators, and external referees will appreciate a candidate's patience and reward it with support in the future. Prudence benefits all sides-especially promotion candidates themselves.

\section{ACKNOWLEDGMENTS}

I thank George Abawi, Zoltan Barany, Zachary Elkins, Gary Freeman, James Hunter, Wendy Hunter, Stephen Jessee, Raúl Madrid, and Bartholomew Sparrow for important and useful comments; however, I alone am responsible for the ideas advanced in this article.

\section{REFERENCE}

Weyland, Kurt. 2011. "The Logic of the Tenure Decision: In Dubio Contra 'Reum.”' PS: Political Science and Politics 44 (2): 357-62. 